University of Nebraska - Lincoln

DigitalCommons@University of Nebraska - Lincoln

Mechanical \& Materials Engineering Faculty

Publications

Mechanical \& Materials Engineering,

Department of

Fall 2004

\title{
Science for Stewardship: Multidisciplinary Research on USS Arizona
}

\author{
Matthew A. Russell \\ National Park Service \\ Larry E. Murphy \\ National Park Service \\ Donald L. Johnson \\ University of Nebraska-Lincoln \\ Timothy J. Foecke \\ National Institute of Standards and Technology \\ Pamela J. Morris \\ Medical University of South Carolina \& NOAA
}

See next page for additional authors

Follow this and additional works at: https://digitalcommons.unl.edu/mechengfacpub

Part of the Mechanics of Materials Commons, Nanoscience and Nanotechnology Commons, Other

Engineering Science and Materials Commons, and the Other Mechanical Engineering Commons

Russell, Matthew A.; Murphy, Larry E.; Johnson, Donald L.; Foecke, Timothy J.; Morris, Pamela J.; and Mitchell, Raphy, "Science for Stewardship: Multidisciplinary Research on USS Arizona" (2004). Mechanical \& Materials Engineering Faculty Publications. 398.

https://digitalcommons.unl.edu/mechengfacpub/398

This Article is brought to you for free and open access by the Mechanical \& Materials Engineering, Department of at DigitalCommons@University of Nebraska - Lincoln. It has been accepted for inclusion in Mechanical \& Materials Engineering Faculty Publications by an authorized administrator of DigitalCommons@University of Nebraska Lincoln. 


\section{Authors}

Matthew A. Russell, Larry E. Murphy, Donald L. Johnson, Timothy J. Foecke, Pamela J. Morris, and Raphy Mitchell 
PAPER

\section{Science for Stewardship: Multidisciplinary Research on USS Arizona}

\section{A U THOR}

Matthew A. Russell

National Park Service, Submerged

Resources Center

Larry E. Murphy

National Park Service, Submerged

Resources Center

\section{Donald L. Johnson}

Metallurgical Engineering Group

University of Nebraska-Lincoln

Timothy J. Foecke

Metallurgy Division, National Institute

of Standards and Technology

Pamela J. Morris

Marine Biomedicine and Environmental

Sciences Center, Medical University of

South Carolina, and Center for Coastal

Environmental Health and Biomolecular

Research and Hollings Marine Laboratory,

NOAA

\section{Ralph Mitchell}

Laboratory of Applied Microbiology,

Division of Engineering and Applied

Sciences, Harvard University

\section{A B S T R A C T}

The National Park Service's Submerged Resources Center and USS Arizona Memorial are conducting and coordinating research directed at understanding the nature and rate of natural processes affecting the deterioration of the USS Arizona in Pearl Harbor, Hawaii. The USS Arizona Preservation Project is designed to be multi-year, interdisciplinary and cumulative, with each element contributing to developing an overall management strategy designed to minimize environmental hazard from fuel oil release and provide the basic research required to make informed management decisions for long-term preservation. The primary project focus is toward acquiring requisite data for understanding the complex corrosion and deterioration processes affecting Arizona's hull, both internally and externally, and modeling and predicting the nature and rate of structural changes. This research program is designed to be a cumulative progression of multi-disciplinary investigative steps. Multiple lines of evidence are being pursued simultaneously, each directly or indirectly linked to the others and to the overall project objectives. This project is an example of government agencies, academic institutions, military commands and private institutions working together effectively for public benefit. The USS Arizona Preservation Project is designed to serve as a model because it will have direct application to preservation and management of historical iron and steel vessels worldwide and to intervention actions for other leaking vessels.

\section{INTRODUCTION}

he National Park Service's (NPS) Submerged Resources Center (SRC) and USS Arizona Memorial (USAR) are conducting and coordinating research directed at understanding the nature and rate of natural processes affecting the deterioration of the USS Arizona in Pearl Harbor, Hawaii. The USS Arizona Preservation Project is designed to be multi-year, interdisciplinary and cumulative, with each element contributing to developing an overall management strategy designed to minimize environmental hazard from fuel oil release and provide the basic research required to make informed management decisions for longterm preservation. This project has been designed to serve as a model because it will have direct application to preservation and management of historical iron and steel vessels worldwide and to intervention actions for other leaking vessels.

\section{Significance}

The USS Arizona, a National Historic Landmark - the highest level of national historic significance-is administered cooperatively by NPS and U.S. Navy and among the most recognized and visited war memorials in the nation (Figure 1). More than 1.5 million people annually visit the USS Arizona Memorial, tomb of more than 1,000 U.S. sailors and marines and the most visible warship lost in World War II. This ship, a national shrine and Naval memorial that remains deeply ingrained in American consciousness, still commands an honor guard from the many capital ships that ply Pearl Harbor today as it did during the war when it served as inspiration to Navy personnel going into battle. The Memorial above the ship commemorates the largest loss in U.S. Naval history and ultimate Allied victory in WWII. 


\section{Goals and Objectives}

The USS Arizona Preservation Project builds upon pioneering site documentation and research led by the National Park Service's Submerged Cultural Resources Unit (later renamed SRC) in the 1980s. The early SRC investigations initiated in situ documentation and study of large, submerged steel warships both in the U.S. and internationally (Figure 2). The current project is designed to provide a foundation for longterm preservation and management of this immensely significant site.

The primary project focus is toward acquiring requisite data for understanding the complex corrosion and deterioration processes affecting Arizona's hull, both internally and externally, and modeling and predicting the nature and rate of structural changes. Developing reasonable and effective management alternatives and deciding the most desirable actions, particularly those regarding intervention or rehabilitation, cannot be done without this information. The current research program is an important step in obtaining necessary scientific information upon which sound management decisions will be made. An important goal of this research is to develop and recommend shortterm and long-term management plans for site preservation based on the results of the research program.

This project addresses another important issue besides preservation of an important national shrine. USS Arizona contains several hundred thousand gallons of fuel oil, which has been slowly escaping since its loss in 1941 . This oil, a potentially serious environmental hazard, is contained within the corroding hull. Catastrophic oil release, although by all indications not imminent, is ultimately inevitable. Understanding the complex and varied hull corrosion processes and modeling structural changes and oil release patterns offers the most efficient method of developing a solution to this potential hazard. This project will develop a research strategy for environmental impact risk assessment and abatement to address the oil issue.

Because of the particular national importance of Arizona, any solution to the oil issue must incorporate a minimum-impact

\section{FIGURE 1}

The USS Arizona Memorial in Pearl Harbor. Credit: Brett Seymour/NPS.

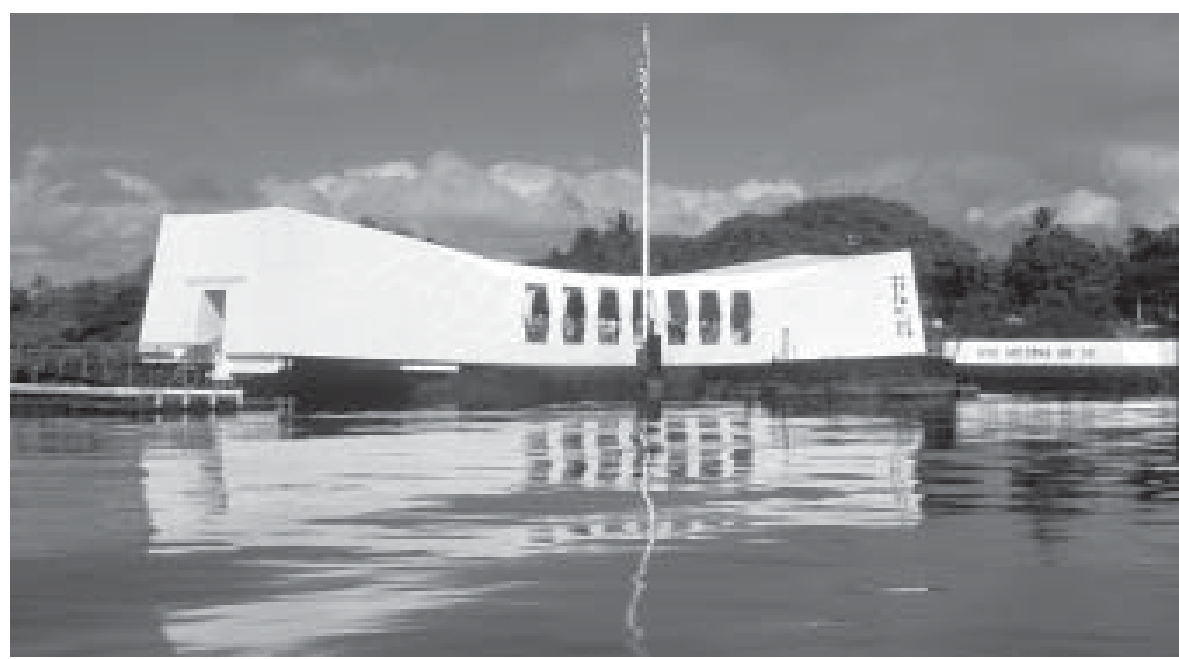

approach or long-term site preservation could be compromised. All research operations are conducted with respect due an American war grave and with minimum impact to the site. Unnecessary disturbance to Arizona's hull is likely to be seen by many as more problematic than the limited oil release now occurring, although managers will ultimately have to face the possibility of a large release. Addressing the oil release problem within a site-preservation framework as incorporated within this research design provides the best balance of competing social values, and it has the highest probability of success for arriving at the best and most defensible solution for both issues.

\section{Methodology}

SRC is providing project principals who have been involved in Arizona research from the early 1980s. NPS is also partnering with military units, researchers, academic institutions, commercial companies, research laboratories, professional societies and other federal agencies in addressing the many multifaceted questions that confront managers responsible for USS Arizona preservation and minimizing environmental risk. This research program is designed to be a cumulative progression of multi-disciplinary investigative steps. Multiple lines of evidence are being pursued simultaneously, each directly or indirectly linked to the oth-

\section{FIGURE 2}

A map of USS Arizona's remains was completed by the National Park Service in the mid-1980s.

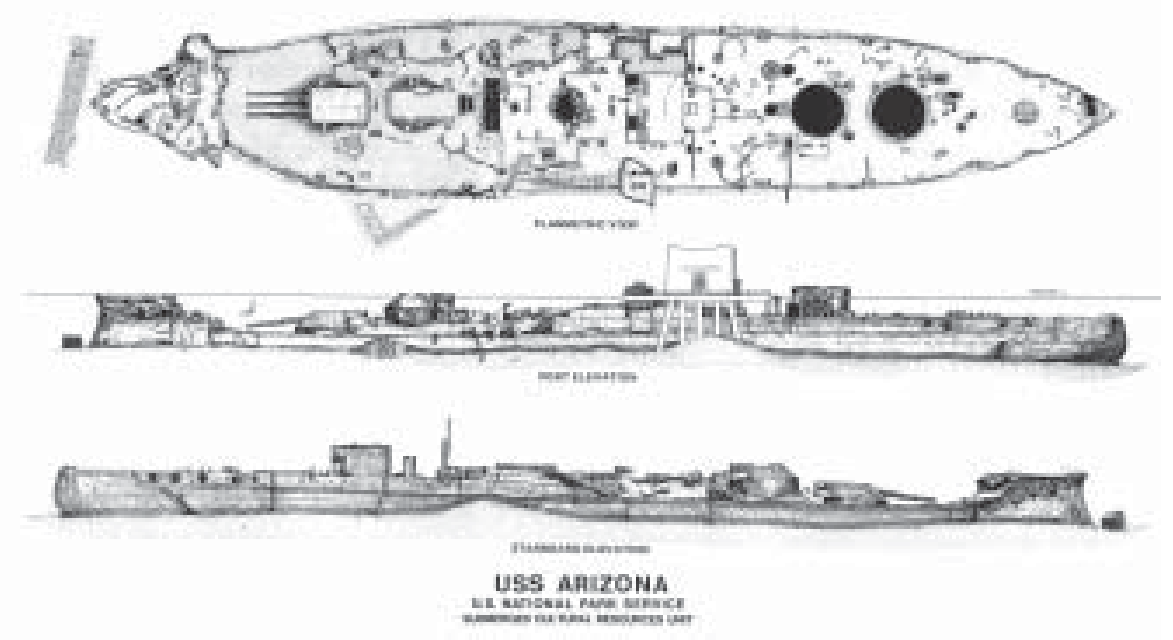


ers and to the overall project objectives. The approach chosen by NPS is to pursue a twofold strategy of research and monitoring.

Primary research is directed towards characterizing overall corrosion processes and determining internal and external corrosion rates. These data are requisite to developing a predictive model of how Arizona is deteriorating and when the corrosion will reach the point where structural changes indicate collapse is imminent. Archeologists and conservation specialists in Australia conducted pioneering research on iron and steel shipwreck deterioration and determined the major factors affecting shipwreck corrosion are metal composition and metallurgical structure, marine growth, water composition, temperature, extent of water movement, seabed composition and depth of burial beneath the seabed (North and MacLeod, 1987). Collecting data necessary to characterize critical corrosion processes on USS Arizona will involve evaluating each of these factors, perhaps identifying additional processes, all of which are complex and interrelated and affect corrosion in many different ways. The result is that when attempting to evaluate the corrosion history of an object it must be considered individually—-there are very few oceanographic and environmental parameters that are uniform between sites. In addition to corrosion research, related research is focusing on the oil that remains trapped within Arizona's hull and on the geological substrate supporting the ship.

Monitoring activities are aimed at collecting baseline data for inclusion in corrosion analysis, and can also be used to assess changing conditions over time, and to quantify various on-site conditions such as physical movement of the ship and oil release amounts. Data collected during monitoring is incorporated into overall research domains that give researchers and managers an indication of overall site stability and how it is changing.

Research and monitoring activities are broken down into individual research domains discussed below. Each research domain either directly contributes to primary research goals or plays a key supporting role in project objectives. All are interconnected on some level.

\section{Finite Element Analysis}

Finite Element Analysis (FEA) is a principal research product that will be the primary predictive tool used during USS Arizona research. A Finite Element Model (FEM) is a computer model used to calculate stresses and shape changes in a structure under load using experimental variables based on observational data. The FEM divides a complex solid into small components called elements, each of which can be one of many simple shapes. Properties for the material of each element are input to describe the element's behavior between its end points (for example, mechanical properties, heat flow, density, etc.). The end points of each "finite" element are called nodes. Conditions are set regarding how nodes connect to one another and loads (known as boundary conditions) are added to the model. The results are plots of displacements of nodes and calculated stresses in the structure at all points.

For historical shipwrecks such as USS Arizona, an FEM will allow manipulation of multiple variables, such as corrosion rate and hull thickness, to analyze loads and stresses on hull structure for prediction of probable collapse rate, nature and sequence and consequent impact on structures containing fuel oil. In addition, the FEM will provide a fundamental tool to evaluate consequences of proposed management alternatives involving structural intervention or preservation strategies. There are particular difficulties in applying an FEM to shipwrecks, however. Geometry is constantly changing due to ongoing corrosion, loads can be very complex, and load and corrosion interact in such a way as to increase the complexity of the model (for example, stress corrosion cracking). There are ways to overcome these difficulties, but accurate data based on direct measurements and observation are of primary importance. For the model to be representative of the real world, input data such as structural dimensions and connections, corrosion rates and loads must be as precise as possible.

Baseline FEM development is being conducted by the National Institute of Standards and Technology (NIST) and is focused on modeling the Arizona hull structure in its as-built original state for an 80-ft. cross-sec- tion, amidships from frame 70 to 90 . The 80 - $\mathrm{ft}$ area selected for initial modeling represents an area affected by the blast that sank the vessel and the ensuing fire. Because this is pioneering research in the sense that FEA has not been applied to corrosion and deterioration of a historical shipwreck before, this preliminary model is a necessary step to refine and test methodologies for developing the overall model required for predicting present and projected future structural strength. It is important to note that the great majority of the work in creating a finite element model of a structure is in the generation of the model and mesh in the computer. Remediation scenarios can then be tested and further stability studies can be made by simply changing the inputs and accounting for new measurements or ideas.

The next development stage of the FEM will focus on incorporating structural effects of the blast and fire that sank the vessel. Modeling the structural changes to Arizona resulting from the explosion and subsequent fire is the logical starting point for understanding the vessel's present condition and projecting its future condition and rate of deterioration.

The final stage of FEM development will incorporate external and internal corrosion and thickness measurements to complete the model of Arizona's present condition and to allow researchers to extend the model into the future. Predictions about current status and future collapse will vary in accuracy depending on the detail of the input data, crafting the correct boundary conditions, and by minimizing simplifying assumptions. For the first issue, the greatest deficiency in data in this case is knowledge of the actual thickness and conditions of hull features both internally and below the mudline. All other assumptions and simplifications have a much smaller effect on the results than these data. The boundary conditions are similarly difficult, as the hull is being supported by a soft, water saturated semi-solid that moves relative to the hull.

As the primary "product" of the current research program, much of the data collected during field work and as a result of the ongoing monitoring is designed to be fed directly 
into revising and refining the FEM to make it as accurate as possible. When combined with corrosion rates and other variables, the model will provide predictability required for evaluating timing, necessity and long-range consequences of management actions.

\section{Corrosion Analysis}

Corrosion research on USS Arizona is focused on understanding and characterizing the specific nature of corrosion occurring on the vessel and determining the corrosion rate for different structural elements of the ship. The goal is to establish a curve of deterioration and "plot" where Arizona currently falls on that curve. The rate of corrosion is a crucial parameter necessary for making long-term predictions about Arizona's structural integrity using the FEM. Because the battleship is a large, complex three-dimensional structure, and it is impossible to directly measure corrosion rates for all critical elements, there will necessarily be some generalizing and use of inferential data to derive rates of deterioration, particularly for inaccessible internal structures. In addition, a comprehensive understanding of all relevant parameters, such as hull steel chemistry and microstructure, constituent analysis of concretion covering the ship and seawater chemistry, is necessary for making indirect estimates of overall corrosion rates.

The most accurate measure of corrosion rate at our disposal is to compare current structural steel thickness with original thickness found on ship's plans, determine how much metal has been lost over a specific period of time and use the calculated corrosion rate in a linear extrapolation to determine overall corrosion rate for that particular location. Cumulative corrosion analyses may provide a more accurate variable rate. Present indications are that corrosion rates are initially high, and decrease to a lesser rate.

Although it was possible to remove some small (4-in. diameter) hull samples (coupons) for direct comparison, in most cases it is not feasible to take direct measurements of steel hull thickness because of the destructive nature of the process and inaccessibility of interior features. Because research on Arizona must be carried out in the most non- invasive manner possible, other less-destructive methods for calculating corrosion rate, including ultrasonic thickness measurements, must be devised, some of which will rely on inferences made from the few direct measurements we have and by comparing other variables critical to the corrosion process. Because the physical environment plays such a large role in how corrosion takes place, baseline environmental data are important in general (see below), but specifically the environment at the hull/concretion interface must be characterized since that is where corrosion occurs (Johnson et al., 2003).

\section{Exterior Corrosion Analysis}

\section{Metallurgical and Metallographic Analysis}

Metallurgical and metallographic analyses are designed to establish basic chemical, structural and strength characteristics of steel used in Arizona's original 1914-1915 construction and later 1929-1931 reconstruction. Investigation of steel hull samples is a necessary step towards determining corrosion nature and rate. Analysis has originally focused on steel collected from superstructure elements stored on land at Waipio Point, Hawaii that were removed from Arizona before construction of the Memorial began in 1960. Samples from both the 1914-1915 and 1929-1931 construction periods were analyzed by scientists from University of Nebraska, Lincoln (UNL). Tests performed include chemical constituent analysis, microstructural examination and Charpy impact testing to determine basic strength characteristics (Johnson et al., 2000).

Additional metallurgical and metallographic analyses are being performed on hull coupons collected in situ from Arizona's hull. Four-inch diameter hull samples, including intact exterior and interior concretion, were removed using a hydraulic-powered hole saw (Figure 3). A total of eight coupons were removed from external, vertical hull locations on both port and starboard sides (Figure 4). On each side, one sample was taken at the Upper Deck level, near the water line; from the Second Deck level, above the torpedo blister; from the Third Deck level, in the torpedo blister; and from the First Platform level, in the torpedo blister and below the mud line. After removal, each location was plugged using a standard plumber's pipe plug and sealed with marine epoxy to prevent formation of a localized corrosion cell. UNL researchers used metallographic methods to examine the hull coupons to measure metal thickness at Rail Sciences laboratories in Omaha, Nebraska (Johnson et al., 2003). Additional metallurgical and metallographic analyses on the same samples are being performed by researchers from NIST.

\section{FIGURE 3}

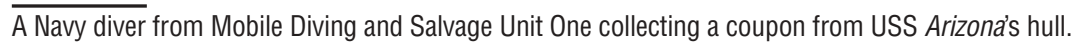
Credit: Brett Seymour/NPS.

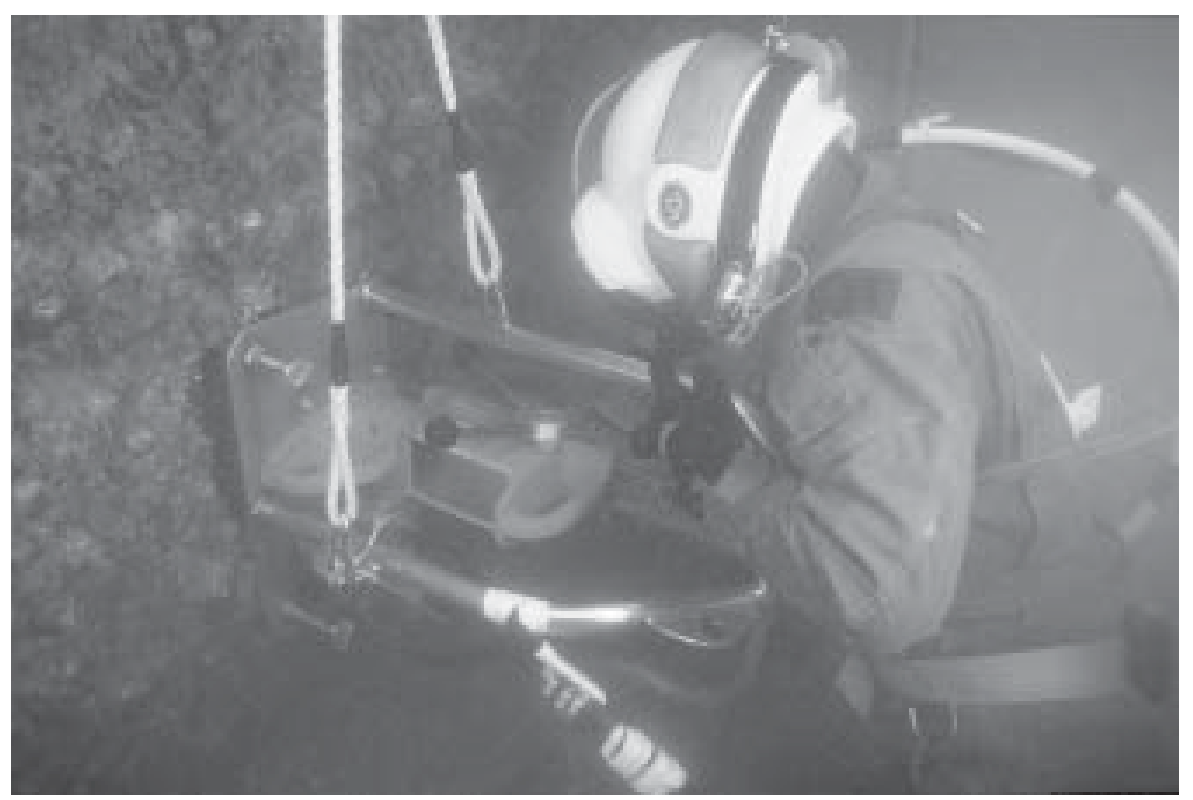




\section{FIGURE 4}

Hull coupon with interior and exterior concretion. Credit: Brett Seymour/NPS.

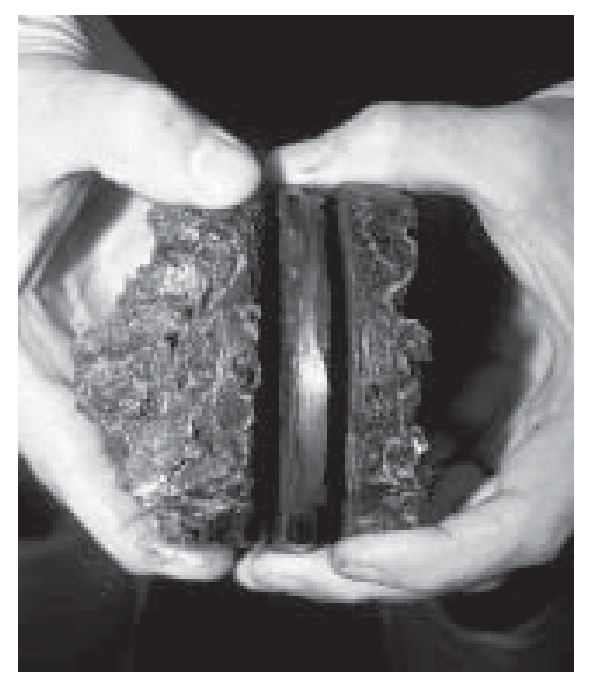

\section{Concretion Analysis}

Fundamental research into the composition and characteristics of the concretion covering Arizona's outer hull is being conducted to aid in understanding the kinetics and mechanisms of the corrosion process on the ship and to determine how concretion chemistry correlates with hull metal loss. The hard layer of concretion that forms on iron and steel objects in seawater is a combination of iron corrosion products and marine organisms, beginning with pioneering coralline algae that leave layers of calcium carbonate when they die. The calcium carbonate residue is overlaid by subsequent layers of coralline algae, and the increasing calcium carbonate layers forms a suitable substrate for secondary growth, such as soft corals and mollusks (North, 1976). Outwardly diffusing iron ions replace some of the calcium resulting in a mix of iron corrosion products, calcium carbonate and living marine organisms covering the iron or steel object. The concretion forms a semi-permeable barrier between the bare metal and seawater and has a significant influence on corrosion by reducing the amount of dissolved oxygen available for the corrosion reaction, increasing acidity at the metal-concretion interface and increasing the chloride ion concentration (North, 1976).

Concretion investigation on USS Arizona has focused on $\mathrm{x}$-ray diffraction to iso- late compounds that make up the concretion and environmental scanning electron microscopy (ESEM) to determine relative percentages of each element. X-ray diffraction was conducted by the Air Force Research Laboratory, Eglin Air Force Base, while ESEM analysis was completed by the Composite Materials and Structures Center at Michigan State University. Preliminary results are consistent with North's (1976) findings that concretion formed on wrought and cast iron structures contains the mineral siderite, which is formed by the exchange of iron ions for calcium ions. UNL scientists are researching how density and electrical resistivity of Arizona's outer hull concretion can be used to characterize the corrosion process and how concretion analysis may be used to determine corrosion rates.

\section{In Situ Hull Corrosion Measurments}

When iron or steel is placed in seawater, corrosion begins as a reaction in which the oxidation of metal forms the anodic portion of a corrosion cell, and the consumption of oxygen forms the reduction, or cathodic, part of the reaction. When the oxidation and reduction rates are equal, there will be a voltage that characterizes the specific reaction rate or corrosion rate-that characteristic voltage is known as the corrosion potential $\left(\mathrm{E}_{\text {corr }}\right)$. In general, a more negative $\mathrm{E}_{\text {corr }}$ value indicates a lower corrosion rate while a more positive $\mathrm{E}_{\text {corr }}$ indicates a higher corrosion rate (MacLeod, 1987).

In situ $\mathrm{E}_{\text {corr }}$ is measured using a silversilver chloride $(\mathrm{Ag} / \mathrm{AgCl})$ reference electrode giving a voltage measurement in millvolts $(\mathrm{mV})$. In addition to $\mathrm{E}_{\text {corr }}, \mathrm{pH}$ is another critical parameter giving an indication of corrosion, and the combined data can be directly related to appropriate Pourbaix Diagrams. The Pourbaix Diagram, a two dimensional map of $\mathrm{E}_{\text {corr }}$ vs. $\mathrm{pH}$, shows regions of stability for corrosion products as a function of $\mathrm{E}_{\text {corr }}$ and $\mathrm{pH}$ and identifies limits for corrosion, immunity from corrosion or limits for formation of protective layers on the metal surface. Diagrams for iron/water and iron/water/ $\mathrm{CO}_{2}$ are especially useful in characterizing corrosion processes at the steel/concretion interface and into the concretion itself. (Johnson et al., 2003). In normal seawater, $\mathrm{pH}$ ranges from 7.5 to 8.2 , but levels below 6.5 and as low as 4.8 are found under concretion covering actively corroding metal. Lower pH levels (more acidic) typically characterize increased corrosion levels (North and MacLeod, 1987).

In situ corrosion measurements taken systematically along Arizona's hull include $\mathrm{pH}$ and $\mathrm{E}_{\text {corr }}$. At selected stations on the vessel, $\mathrm{pH}$ and $\mathrm{E}_{\text {corr }}$ are measured at various concretion-depths using $\mathrm{pH}$ and $\mathrm{Ag} / \mathrm{AgCl}$ reference electrodes inserted into holes drilled into the concretion. Hole depths are controlled by several depth jigs to provide uniform data to the metal surface. Multiple samples are drilled in a vertical transect at each station at varying water depths to characterize how the corrosion process changes with water depth and concretion thickness. In addition, these data are compared over multiple field seasons. Efforts are underway to correlate $\mathrm{E}_{\text {corr }}$ with corrosion rate (Johnson et al. 2002).

Another critical in situ measurement of USS Arizona's hull includes ultrasonic thickness measurements. The eight hull coupons collected in two vertical transects on Arizona's hull provide an empirical measure of corrosion rate at each of these locations when compared to as-built hull thicknesses. Because of the invasive nature of collecting hull coupons, however, it is necessary to develop a more non-invasive technique to expand hull thickness data. Since hull thickness measurements give a direct measure of corrosion rate, this data is essential to developing an accurate FEM. Because the specific metal thickness has been precisely measured at the eight coupons locations, they are a control for ongoing testing of ultrasonic thickness techniques and instruments (Figure 5).

\section{Interior Corrosion Analysis}

Analysis of the nature and rate of interior corrosion in USS Arizona is so far limited to indirect measurements of environmental parameters and $\mathrm{E}_{\text {corr }}$, subjective observation of interior conditions based on images taken by a small VideoRay ROV, and 


\section{FIGURE 5}

NPS archeologist Matt Russell taking ultrasonic thickness measurements on Arizona's hull. Credit: Brett Seymour/NPS.

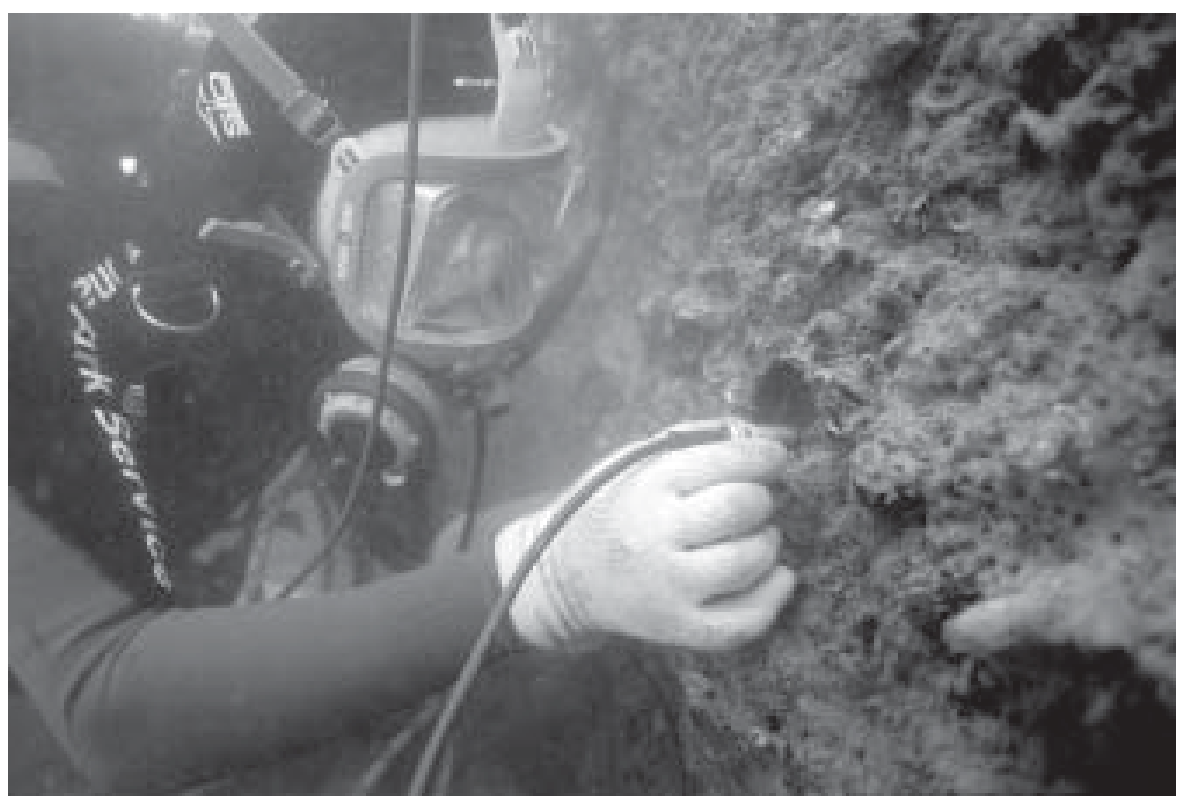

experimental evaluation of ultrasonic thickness techniques using the ROV as an instrument platform. NPS management has limited diver access to the Arizona's hull, so interior data can at present only be collected remotely. The VideoRay ROV is the primary tool used for collecting internal data (Figure 6). It can be used as an instrument platform to carry a YSI 600XLM Multiparameter Sonde to measure $\mathrm{pH}$, temperature, salinity, dissolved oxygen, oxygen reduction potential and conductivity - the same parameters being recorded externally (see below). The ROV can also carry a GMC STAPERM silversilver chloride reference electrode to measure interior $\mathrm{E}_{\text {corr }}$. An evaluation was made for use of an ROV-mounted Cygnus Ultrasonic Thickness Gauge to measure interior bulkhead thicknesses, but so far this technology has not proved suitable for this application.

\section{Environmental Monitoring}

A variety of factors have been identified that directly influence metal corrosion on shipwrecks, including water composition (dissolved oxygen, $\mathrm{pH}$, salinity and conductivity), temperature and extent of water movement (North and MacLeod, 1987).

\section{FIGURE 6}

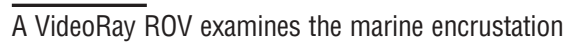
on a mirror above the sink in the sediment filled Division Marine Office. Credit: Brett Seymour/NPS.

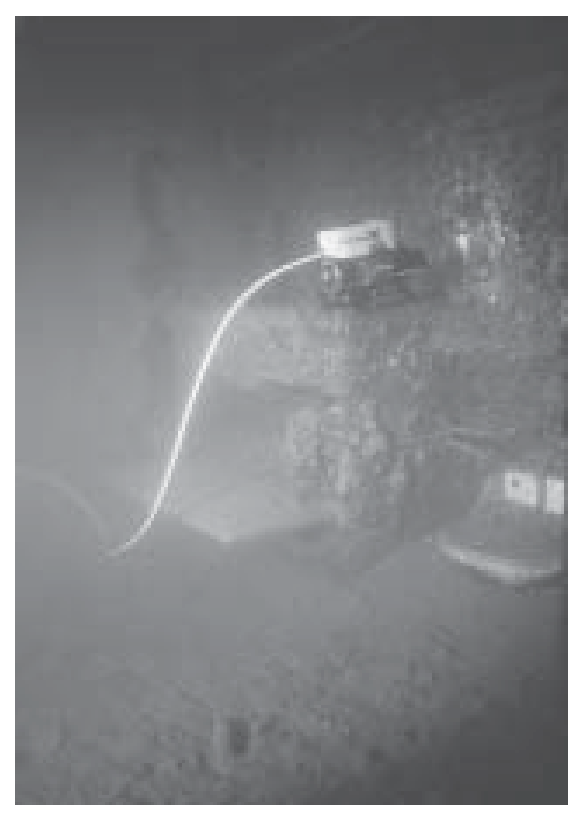

Oxygen reduction is typically the main cathodic reaction occurring in steel exposed to seawater, so dissolved oxygen availability at the cathodic site controls the corrosion rate, with higher dissolved oxygen content resulting in higher corrosion. Water at the ocean's surface is generally oxygen-saturated, so over- all dissolved oxygen content depends on the amount of mixing that occurs with surface water-increased water movement and mixing results in elevated dissolved oxygen levels. In addition, temperature and dissolved oxygen are inversely proportional, so lower temperature results in increased dissolved oxygen. The $\mathrm{pH}$ level is indicative of overall corrosion activity. In normal seawater, $\mathrm{pH}$ ranges from 7.5 to 8.2 , but levels below 6.5 are found under concretion covering actively corroding metal. Lower pH levels (more acidic) typically characterize active or increased corrosion levels. Salinity is closely related to the corrosion rate of steel in water, so increased salinity usually results in higher corrosion rates. This is evident when comparing metal preservation in freshwater compared to seawater environments-freshwater lakes typically exhibit better preservation of iron and steel. There are several ways that higher salinity affects corrosion, including increasing conductivity (which facilitates movement of ion between anodic and cathodic areas), increasing dissolved oxygen and supplying ions that can catalyze corrosion reactions, among others (North and MacLeod, 1987). Higher conductivity can increase corrosion by increasing the movement of ions during the corrosion process.

In general, corrosion increases as temperature increases. Under controlled laboratory conditions, corrosion rate doubles for every $10^{\circ} \mathrm{C}$ rise in temperature. This relationship is complicated, however, by the effect of temperature on both dissolved oxygen and biological growth. Warmer water supports increased marine growth, which contributes to concretion formation on steel in seawater and that, in turn, generally reduces corrosion rates. In addition, as discussed above, lower temperature results in higher dissolved oxygen content, which consequently means increased corrosion (North and MacLeod, 1987).

Water movement from waves and currents on a site affects corrosion in several ways, but generally high-energy environmental conditions results in higher corrosion rates. Active water movement can contribute to mechanical erosion of metal surfaces and can also impede development of 
protective concretion layers by removing accumulating ions before they can precipitate and begin the concretion formation process. Waves and currents also contribute to water mixing and aeration that result in increased dissolved oxygen levels (North and MacLeod, 1987).

Factors that affect corrosion on metal shipwrecks are complicated and interrelated. Reducing one key factor can increase another, and the results are often unpredictable. It is clear, however, that in order to understand the corrosion history of an object, even a complex object like a World War II battleship, and to begin to define the nature and rate of deterioration affecting the object, an understanding of the various environmental factors at play is necessary. An important aspect of the current research program is long-term monitoring of oceanographic and environmental parameters on USS Arizona. This is being accomplished with in situ multiparameter instruments placed on the hull and on the seabed to the side of the vessel.

\section{Exterior Monitoring}

The U.S. Geological Survey (USGS) and NPS are analyzing data from oceanographic and water-quality monitoring instruments placed on and near Arizona to determine long-term, seasonal variability in key parameters that affect corrosion. Researchers calibrated and deployed a SonTek Triton waveheight and current meter and a YSI 6600 Multiparameter Sonde on Arizona in November 2002. These instruments have internal memory and batteries and can be left in situ for up to 60 days, recording data multiple times an hour. The instruments are retrieved and downloaded, then recalibrated and deployed every 60 days by USAR staff. The data are sent to the SRC in Santa Fe, New Mexico, and the USGS in Santa Cruz, California, for compilation and analysis. The instruments are collecting baseline data including wave height and direction and current velocity and direction around the vessel, and basic environmental parameters including $\mathrm{pH}$, temperature, salinity, dissolved oxygen, oxygen reduction potential and conductivity. The goal is to collect at least a two- year database to discern seasonal variation and patterns of environmental parameters within Pearl Harbor. As discussed above, each of these parameters can affect corrosion rates on the ship.

\section{Interior Monitoring}

Environmental monitoring is also being conducted within Arizona's interior cabins to determine internal environmental conditions. Internal conditions can be compared to external conditions in an attempt to infer interior corrosion nature and rate. These data are critical to developing a viable FEM that takes into account both interior and exterior hull corrosion. A VideoRay ROV is equipped with a YSI 600XLM Multiparameter Sonde to measure $\mathrm{pH}$, temperature, salinity, dissolved oxygen, oxygen reduction potential and conductivity- the same parameters being recorded externally. Initial investigations are focused on second deck cabins accessible via open portholes and inside Barbette No. 3. Subsequent investigations will record environmental parameters in Third Deck spaces_-although very few of these areas are currently accessible to the ROV. One of the goals of interior investigation is to locate access to Arizona's lower decks. Data from both external and internal environmental monitoring will be assessed, and the results will be factored in developing the Arizona FEM.

\section{Structural Monitoring}

Monitoring observable changes to USS Arizona's accessible external areas is designed to allow researchers and managers to quantify physical changes to Arizona's fabric. As internal and external structures corrode and weaken, various parts of Arizona's hull may experience shifting, settling or collapse. Since a regular NPS presence on Arizona began in 1982, a qualitative assessment by researchers indicates that Upper Deck areas in and around the ship's galley are showing signs of change_-widening cracks and limited deck collapse are occurring. So far any measurable change has only occurred to non-structural portions of the vessel_-"non-structural" in the sense that Upper Deck areas do not contribute to the battleship's overall structural integrity, especially oil-containing structures. Most Upper Deck structures were removed from Arizona before construction of the Memorial, which spans the ship just aft of the galley area. Regardless, active monitoring of the entire ship, including these Upper Deck areas, is ongoing to watch for evidence of significant structural changes.

\section{External Monitoring}

The primary method used to monitor physical changes to USS Arizona's hull is a series of very high-resolution Global Positioning System (GPS) points. Using dual-frequency GPS receivers, researchers have set a series of monitoring points across Arizona's exposed decks. Initially using stainless steel studs, later changed to PVC disks, in selected locations, NPS surveyors leveled a large, purpose-built underwater tripod over each point (Figure 7). Extension poles set on top of the tripod extending above the water's surface allowed the GPS antenna to be placed precisely over the desired point. Using advanced survey techniques, each point was collected with sub-centimeter accuracy in three dimensions. These points will be re-surveyed every two years to

\section{FIGURE 7}

NPS archeologist Larry Murphy setting up an underwater tripod on USS Arizona used to collect highresolution GPS positions.

Credit: Brett Seymour/NPS.

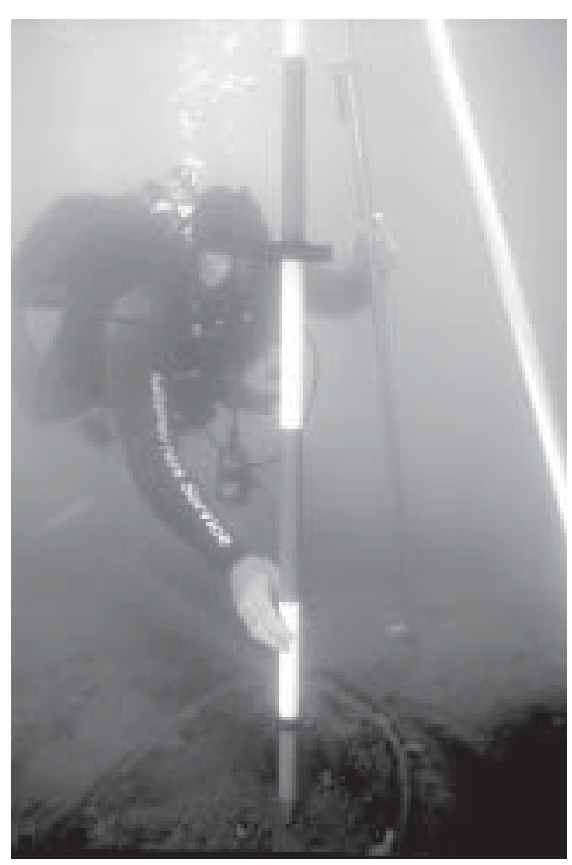


determine if, and how, the ship is moving, shifting, or settling. Although the accuracy of each point was mathematically calculated to about $0.5 \mathrm{~cm}$ (Circle of Error Probable), it will be necessary to apply a more conservative threshold of change to future monitoring re-occupations. Because of environmental conditions and differences in equipment and stadia variations, a more realistic threshold is $10 \mathrm{~cm}$. Instrument error, set-up error, or most likely, nearly imperceptible antenna movement caused by water movement can create cumulative errors of up to $10 \mathrm{~cm}$. Consequently, we cannot reliably attribute any observed change that is less than $10 \mathrm{~cm}$ vessel movement; however, corroborative evidence would be sought for any level of change.

In addition to GPS, structural changes are being monitored using a series of crack monitors normally employed in measuring how cracks are widening on historic building walls. These plastic monitors were affixed over numerous cracks in the Upper Deck galley where Arizona's deck collapse has been observed. The crack monitors are checked periodically to see if the cracks are widening or shifting.

\section{Internal Monitoring}

Internal structural monitoring of USS Arizona is a qualitative process using the VideoRay ROV to visually examine interior areas and note observable changes over time. Interior investigation is taking place over multiple years in all accessible areas for measuring and monitoring interior environmental factors and corrosion parameters. During this process, overall internal structural condition will be observed and noted. We will continue seeking appropriate ROV-deployable metal thickness measurement technology.

\section{Oil Analyses}

Analysis of oil leaking from Arizona's hull and trapped in accessible overhead spaces is designed to collect baseline data about the approximately 500,000 gallons of Bunker C fuel oil still remaining within the battleship and to be used indirectly to investigate the condition of interior oil bunkers. Collaborative research is focusing on using oil characterization to measure environmental degra- dation of oil trapped within different areas of Arizona's hull to ascertain residence time of each oil cache by determining the length of time each oil release has been in contact with seawater. Medical University of South Carolina (MUSC) researchers are analyzing oil samples using gas chromatography coupled to mass spectrometry in order to assess the environmental weathering of the oil and to obtain a "fingerprint" of the oil leaking from the ship by examining the biomarker profile. While Bunker $\mathrm{C}$ is susceptible to biotic and abiotic weathering processes in the environment, it tends to be persistent due to the increased concentration of high molecular weight hydrocarbons. Using gas chromatography-flame ionization detection (GCFID) and gas chromatography-mass spectrometry (GC-MS) to chemically characterize oil leaking from different regions of the ship, researchers have determined that oil leaking near Barbette No. 4 showed almost no detectable signs of weathering, while oil trapped in Second Deck overheads and leaking from other locations were depleted of $n$ alkanes and low molecular weight polycyclic aromatic hydrocarbons. Results of analyses may differentiate individual oil bunkers, as well as differentiate age of oil (relative to sea water exposure) in cabin overheads and being released from various locations around the battleship, which has important implications for structural analysis. This approach may provide inferential indicators about the state of deterioration and structural changes of oil bunkers that are presently inaccessible in the battleship's lower deck areas.

In addition to baseline oil analysis, ongoing monitoring is being conducted to measure the amount of oil escaping from the ship at several locations. Using a custom-built oil collection device, researchers periodically capture all oil escaping from each location around Arizona's hull during a 24-hour collection period. This quantifies the leakage rate for long-term monitoring to see whether oil leakage from specific locations is stable or increasing. Currently, we are collaborating on development of a remote oil monitoring system that can quantify the total, variable amount of oil being released in real-time.

\section{Microbiology}

Microbiological analyses are being pursued for several purposes. One of the main applications is to examine the role of microbially induced corrosion (MIC) in the

\section{FIGURE 8}

Illumination inside a Junior Officer's Stateroom reveals oil pooling between deck beams of the ceiling overhead. A white microbial community is visible growing on the oil surface at the left of the photograph. Credit: Brett Seymour/NPS.

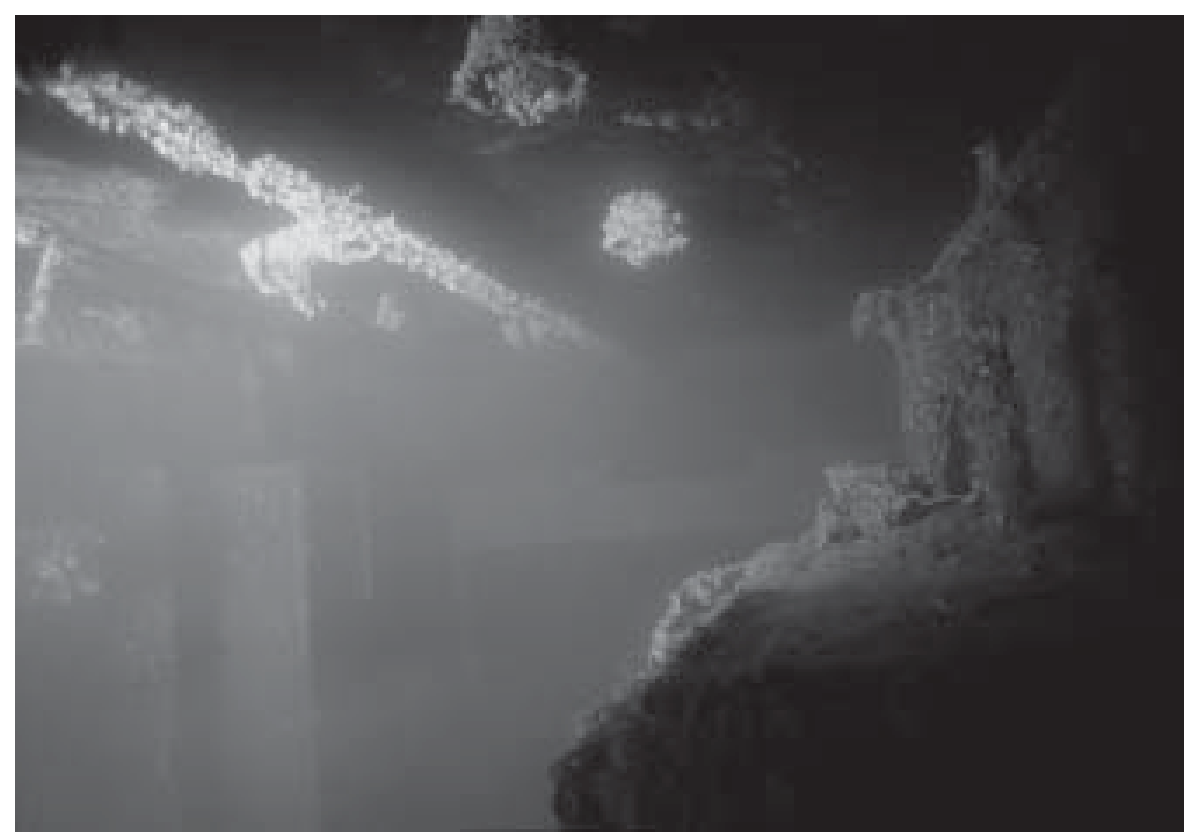


degradation of Arizona's oil bunkers. Biofilms are communities of microorganisms attached to an interface and embedded in a polysaccharide matrix produced by the microorganisms. They are ubiquitous in nature and are a common cause of corrosion. The depletion of oxygen from microhabitats within biofilms has important consequences for the corrosion of metals. Anaerobic conditions can result in the growth of sulfate-reducing bacteria (SRB), a frequent cause of MIC. Metal corrosion is driven by the hydrogenase activity of the SRB. Harvard University researchers are currently in the process of determining the ability of hydrocarbon degrading microorganisms isolated from USS Arizona to degrade steel. The objective is to determine the rate of corrosion in the oil-containing bunkers in USS Arizona.

In addition to research into MIC, other microbiological investigations are being carried out on USS Arizona. MUSC scientists are currently developing innovative research that examines the role of microorganisms in fuel oil degradation and the aerobic biodegradation potential of microorganisms associated with the battleship's hull (Figure 8). They are using denaturing gradient gel electrophoresis analysis to examine the microbial community structure of oil-degrading microorganisms from sediments adjacent to the USS Arizona that are using oil leaking from the ship as the sole source of carbon. The biodegradation potential of these microbial communities has demonstrated extensive degradation of polycyclic aromatic hydrocarbons from Bunker $\mathrm{C}$ crude as well as a novel pattern of biomarker degradation.

\section{Geological Analyses}

The USGS and NPS are conducting an analysis of the geological substrate surrounding and beneath USS Arizona to determine its nature and characteristics. The basic question being investigated is how stable are supporting sediments beneath the battleship, and is it possible Arizona is experiencing movement due to shifting sediments? Arizona's overall stability within its supporting matrix is important because it can potentially affect GPS structural monitoring and the FEM. To be accurate, interpretation of GPS monitoring-point movement and predictions regarding structural stability, such as those produced from an FEM, must control for geological support variables. If movement is observed in GPS monitoring, it will be necessary to isolate potential internal changes (shifting, settling, and collapsing decks and internal bulkheads) from external movement (the entire ship settling into surrounding sediments). In addition, the FEM must take into account sediment characteristics surrounding and supporting Arizona's hull, including potential differential support, to give an accurate indication of the vessel's overall structural integrity.

To conduct a comprehensive analysis of the geological substrate around USS Arizona, researchers are using a combination of geophysical remote sensing and geotechnical analysis of recovered $50-\mathrm{ft}$ cores. Stratigraphic description and geotechnical analysis of cores recovered from around Arizona are providing data about sediment consolidation and compression properties and triaxial shear strength of distinct strata beneath the seabed. Chirp seismic reflection data collected in a wide area surrounding Arizona and precise correlation of sub-bottom records to geological core analysis project these engineering properties across the subsurface geological strata of Pearl Harbor surrounding the battleship. The combination of these data should give an overall indication of how stable Arizona is within its supporting geological matrix.

\section{Geographic Information System Development}

Geographic Information Systems (GIS) allow researchers to incorporate different types of data such as maps, plans, graphs, video and photographs into a single, cumulative, spatially referenced database for rapid display and manipulation. GIS is the use of multiple, spatially referenced databases to produce maps that graphically depict usergenerated combinations of variables presented as themes, layers or coverages.

GIS has proven to be the appropriate methodology to compare variables among many sets of spatial data, such as artifact categories, remote sensing results and natural environmental characterizations, to examine distribution and change over space, and, if sufficient data are available, over time. Rapid manipulation of scale and variables can facilitate pattern recognition that may not be apparent at other levels. Examination of combined variables is instant because they are presented graphically, greatly simplifying analysis by precluding the necessity of generating mathematical and statistical models to characterize patterned relationships. Current computer and software speed allow rapid manipulation of multiple variable combinations, which allows generation of associations and relationships that might otherwise be unanticipated.

GIS data sets can be presented as tabular database files or themes that can be generated, analyzed, scaled, combined, superimposed and displayed through direct user access in unlimited variations in a GIS program, such as ArcView. Data themes are presentations of nonspatial data referenced to a common location expressed as geographic coordinates. One way of looking at themes is to consider them $x-y$ horizontal locations that share a category of variable $z$ values, which represent discrete, quantifiable attributes, for example water depth or magnetic intensity.

Primary electronic data are being consolidated into a single GIS database, including archeological maps and drawings, aerial images, relevant plans and technical drawings, photographs, video and results from ongoing fieldwork. The fieldwork results incorporated into the GIS include remote sensing data from sub-bottom profiler and single-beam bathymetric survey, data collected each year on eight GPS monitoring points, geological core locations and characteristics, and oceanographic and environmental monitoring instrument locations and data. In addition, contractors are developing a "geodatabase" of USS Arizona that includes digital information for each cabin and space on the plans — each object, space or cabin is a digitally separate entity with attributes linked to it through the geodatabase. Using these base maps and the geodatabase, scanned ship's plans can be "linked" to their 
appropriate object or location on the ship. In this way, hundreds of scanned original USS Arizona plans can be incorporated into a single electronic database for easy accessibility, manipulation, and analysis.

The GIS is being developed primarily for use by researchers involved with the current project, and as a seamless, cumulative, user-friendly way to organize and access data collected each field season. As a side benefit, certain portions of the GIS project can be made available to the public in the future via the internet.

\section{Conclusion}

This research approach for USS Arizona is designed to produce cumulative data whose synthesis will lead to management actions to preserve the vessel for future generations. We believe this experimental approach will produce results that will contribute to the disciplines involved and be applicable to numerous iron and steel legacy vessels submerged worldwide. This research partnership for the Pearl Harbor vessels is an example of government agencies, academic institutions, military commands, and private institutions working together effectively for public benefit. This collaboration is a model for combining public and private resources to cost-efficiently address issues important to the American people.

\section{References}

Johnson, D. L., J. D. Makinson, R. De

Angelis, B. Wilson and W. N. Weins. 2003.

Metallurgical and Corrosion Study of

Battleship USS Arizona, USS Arizona

Memorial, Pearl Harbor. Unpublished

Manuscript on file at National Park Service.

Johnson, D.L., W. N. Weins, and J. D.

Makinson. 2000. Metallographic Studies of

the USS Arizona. In: Microstructural Science

Vol. 27: Understanding Processing, Structure,

Property, and Behavior Correlations. ed.

William N. Weins. pp. 85-91. New York:

ASM International.

MacLeod, I. D. 1987. Conservation of

Corroded Iron Artifacts - New Methods for

On-Site Preservation and Cryogenic

Deconcreting. International Journal of

Nautical Archaeology and Underwater

Exploration, 16(1):49-56.

North, N. A. 1976. Formation of Coral

Concretions on Marine Iron. International

Journal of Nautical Archaeology and

Underwater Exploration, 5(3):253-258.

North, N.A. and I.D. MacLeod. 1987.

Corrosion of Metals. In: Conservation of

Marine Archaeological Objects. ed. Colin

Pearson. pp. 68-98. London: Butterworth \& Co.

Makinson, J. D., D. L. Johnson, M.A. Russell,

D. L. Conlin and L. E. Murphy. 2002. In Situ

Corrosion Studies on the Battleship USS

Arizona. Materials Performance, 41(10):56-60. 